\title{
Two-Electron Reaction without Structural Phase Transition in Nanoporous Cathode Material
}

\author{
Tomoyuki Matsuda ${ }^{1}$ and Yutaka Moritomo ${ }^{1,2}$ \\ ${ }^{1}$ Graduate School of Pure and Applied Science, University of Tsukuba, Tsukuba, Ibaraki 305-8571, Japan \\ ${ }^{2}$ Tsukuba Research Center for Interdisciplinary Materials Science (TIMS), University of Tsukuba, Tsukuba, Ibaraki 305-8571, Japan
}

Correspondence should be addressed to Yutaka Moritomo, moritomo@sakura.cc.tsukuba.ac.jp

Received 21 February 2012; Accepted 28 March 2012

Academic Editor: Vaishali R. Shinde

Copyright (C) 2012 T. Matsuda and Y. Moritomo. This is an open access article distributed under the Creative Commons Attribution License, which permits unrestricted use, distribution, and reproduction in any medium, provided the original work is properly cited.

\begin{abstract}
We investigated the charge/discharge properties, valence states, and structural properties of a nanoporous cathode material $\mathrm{Li}_{x} \mathrm{Mn}\left[\mathrm{Fe}(\mathrm{CN})_{6}\right]_{0.83} \cdot 3.5 \mathrm{H}_{2} \mathrm{O}$. The film-type electrode of $\mathrm{Li}_{x} \mathrm{Mn}\left[\mathrm{Fe}(\mathrm{CN})_{6}\right]_{0.83} \cdot 3.5 \mathrm{H}_{2} \mathrm{O}$ exhibited a high charge capacity $(=$ $128 \mathrm{mAh} \mathrm{g}^{-1}$ ) and a good cyclability ( $87 \%$ of the initial value after 100 cycles) and is one of the promising candidates for Liion battery cathode. X-ray absorption spectra near the Fe and $\mathrm{Mn} \mathrm{K}$-edges revealed that the charge/discharge process is a twoelectron reaction; that is, $\mathrm{Mn}^{\mathrm{II}}-\mathrm{NC}-\mathrm{Fe}^{\mathrm{II}}, \mathrm{Mn}^{\mathrm{II}}-\mathrm{NC}-\mathrm{Fe}^{\mathrm{III}}$, and $\mathrm{Mn}^{\mathrm{III}}-\mathrm{NC}-\mathrm{Fe}^{\mathrm{III}}$. We further found that the crystal structure remains cubic throughout the charge/discharge process. The lattice constant slightly increased during the $\left[\mathrm{Fe}^{\mathrm{II}}(\mathrm{CN})_{6}\right]^{4-} /\left[\mathrm{Fe}^{\mathrm{III}}(\mathrm{CN})_{6}\right]^{3-}$ oxidization reaction while decreased during the $\mathrm{Mn}^{\mathrm{II}} / \mathrm{Mn}^{\mathrm{III}}$ oxidization reaction. The two-electron reaction without structural phase transition is responsible for the high charge capacity and the good cyclability.
\end{abstract}

\section{Introduction}

Lithium ion batteries have aided the portable electronics revolution during the past two decades, and they are now being intensively pursued for transportation applications and the efficient storage and utilization of intermittent renewable energies like solar and wind. Therefore, nextgeneration electrode materials have been intensively explored in order to achieve a highly capacious, safe, environmentallyfriendly, and low cost Li-ion secondary battery. Especially, the automotive industry requires low-cost and highercapacious materials than the conventionally used transition metal oxides, for example, $\mathrm{LiCoO}_{2}[1,2] . \mathrm{LiFePO}_{4}$ with ordered-olivine structure is one of the most promising candidate cathode materials and is beginning to be applied commercially. The compound has one-dimensional tubes for Li insertion/extraction. Padhi et al. first reported that the charge capacity of $\mathrm{LiFePO}_{4}$ was $100-110 \mathrm{mAh} \mathrm{g}^{-1}$ [3]. The $\mathrm{Li}$ insertion/extraction reaction in $\mathrm{LiFePO}_{4}$ proceeds via the two-phase process, unless the particle size becomes below $40 \mathrm{~nm}$ [4]. In addition, the low electronic conductivity due to the ionic nature of the compound is considered to disturb high-speed charging/discharging. Therefore, other iron-based materials that exhibit reversible $\mathrm{Li}$ ion insertion/extraction reaction could be attractive electrode materials.

Prussian blue analogues [5-15], represented as $A_{x} M\left[M^{\prime}(\mathrm{CN})_{6}\right]_{y} \cdot z \mathrm{H}_{2} \mathrm{O}$ ( $A$ is an alkali metal ion, and $M$ and $M^{\prime}$ are transition metal ions), have nanoporous three-dimensional network structures. The film type of this series is studied as electrochromic materials [7]. Imanishi et al. firstly reported the charge/discharge properties of the Prussian blue analogues $(M=\mathrm{V}, \mathrm{Mn}, \mathrm{Fe}, \mathrm{Co}, \mathrm{Ni}, \mathrm{Cu}$, and $\left.M^{\prime}=\mathrm{Fe}\right)[12,13]$, and the $M=\mathrm{Cu}$ compound exhibited a large capacity $\left(140 \mathrm{~mA} \mathrm{~h} \mathrm{~g}^{-1}\right)$ even though its cyclability is very poor. On the other hand, Okubo et al. reported excellent cyclability in the $M=\mathrm{Mn}$ and $M^{\prime}=\mathrm{Fe}$ compound even though its capacity is low $\left(57 \mathrm{~mA} \mathrm{~h} \mathrm{~g}^{-1}\right)$ [14]. Recently, we realized a good cyclability with a high charge capacity in the film-type electrode of $\mathrm{Li}_{x} \mathrm{Mn}\left[\mathrm{Fe}(\mathrm{CN})_{6}\right]_{0.83} \cdot 3.5 \mathrm{H}_{2} \mathrm{O}$ [15]. The film-type electrode does not contain a conductive material nor a binder polymer. 


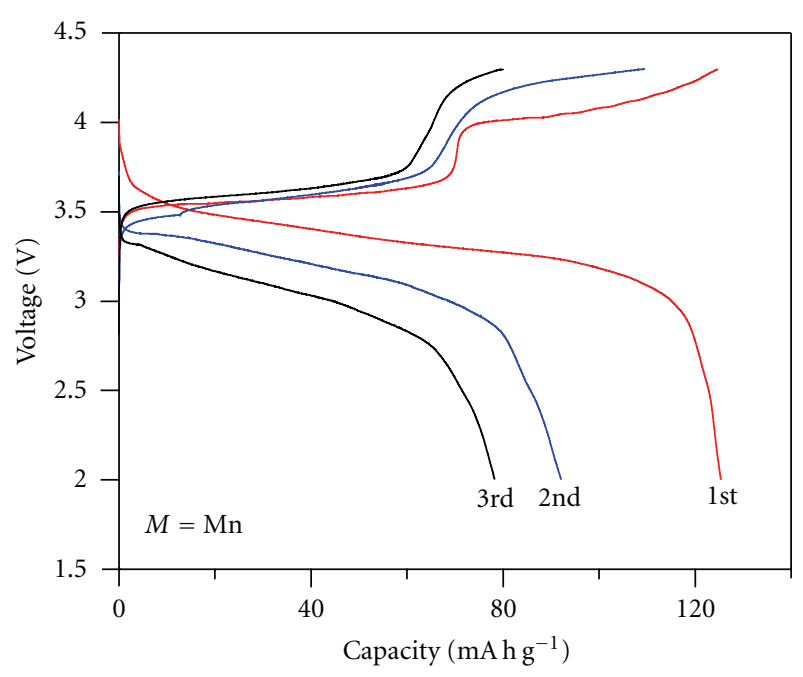

(a)

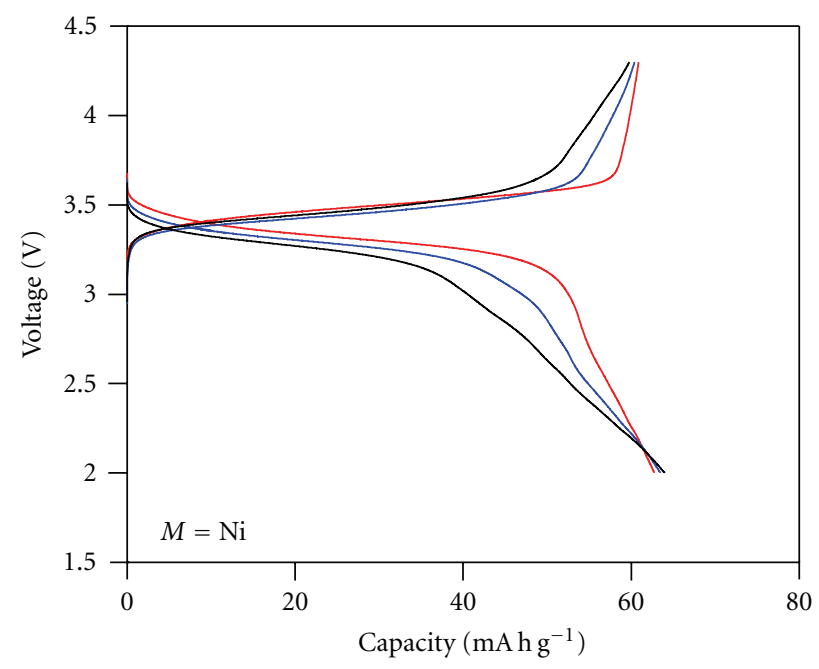

(c)

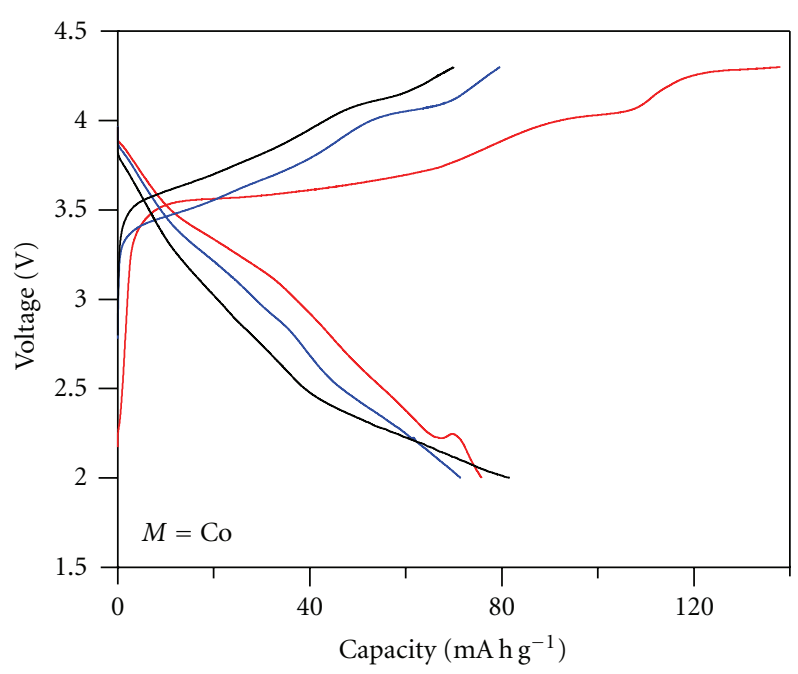

(b)

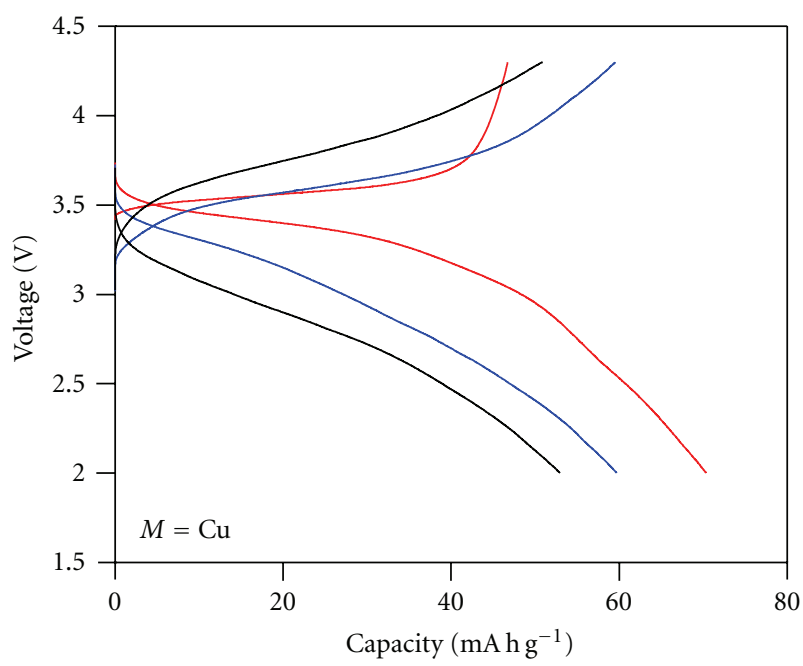

(d)

Figure 1: Charge/discharge curves of the paste-type electrode of $\mathrm{Na}_{x} M\left[\mathrm{Fe}(\mathrm{CN})_{6}\right](M=\mathrm{Mn}(\mathrm{a}), \mathrm{Co}(\mathrm{b})$, $\mathrm{Ni}(\mathrm{c})$, and Cu (d)) against the Li metal at the 1st (red), 2nd (blue), and 3rd (black) cycles.

In this paper, we present charge/discharge properties of the $\mathrm{Na}_{4 x-2} M\left[\mathrm{Fe}(\mathrm{CN})_{6}\right]_{x} \cdot z \mathrm{H}_{2} \mathrm{O}(M=\mathrm{Mn}, \mathrm{Co}, \mathrm{Ni}$, and $\mathrm{Cu})$ powder samples and a detailed electronic and structural properties of $\mathrm{Li}_{x} \mathrm{Mn}\left[\mathrm{Fe}(\mathrm{CN})_{6}\right]_{0.83} \cdot 3.5 \mathrm{H}_{2} \mathrm{O}$ during the charge/discharge processes. The data clearly indicates that the two-electron reaction without structural phase transition is responsible for the high charge capacity and the good cyclability observed in $\mathrm{Li}_{x} \mathrm{Mn}\left[\mathrm{Fe}(\mathrm{CN})_{6}\right]_{0.83} \cdot 3.5 \mathrm{H}_{2} \mathrm{O}$.

\section{Experimental Section}

2.1. Preparation of the Powder Samples. The powder form of $\mathrm{Na}_{4 x-2} M\left[\mathrm{Fe}(\mathrm{CN})_{6}\right]_{x} \cdot z \mathrm{H}_{2} \mathrm{O}(M=\mathrm{Mn}, \mathrm{Co}, \mathrm{Ni}$, and $\mathrm{Cu})$ was prepared by precipitation method. The aqueous solutions of $\mathrm{NaCl}\left(4 \mathrm{moL} \mathrm{dm}{ }^{-3}\right)$ and $\mathrm{MCl}_{2} \cdot z \mathrm{H}_{2} \mathrm{O}\left(5 \mathrm{mmoL} \mathrm{dm}{ }^{-3}\right)$ were slowly added dropwise to a stirred solution of $\mathrm{NaCl}\left(4 \mathrm{moL} \mathrm{dm}^{-3}\right)$ and $\mathrm{K}_{4}\left[\mathrm{Fe}(\mathrm{CN})_{6}\right]\left(5 \mathrm{mmoL} \mathrm{dm}^{-3}\right)$. The obtained powder precipitates were filtered and washed with water and then dried in air.

2.2. Preparation of the Thin Film. Thin film of $\mathrm{Na}_{1.32} \mathrm{Mn}\left[\mathrm{Fe}(\mathrm{CN})_{6}\right]_{0.83} \cdot 3.5 \mathrm{H}_{2} \mathrm{O}$ was electrochemically synthesized on an indium tin oxide (ITO) transparent electrode under potentiostatic conditions at $-0.50 \mathrm{~V}$ versus a standard $\mathrm{Ag} / \mathrm{AgCl}$ electrode in an aqueous solution containing $1.0 \mathrm{mmoL} \mathrm{dm}^{-3} \mathrm{~K}_{3}\left[\mathrm{Fe}(\mathrm{CN})_{6}\right], 1.5 \mathrm{mmoL} \mathrm{dm}{ }^{-3}$ $\mathrm{MnCl}_{2} \cdot 6 \mathrm{H}_{2} \mathrm{O}$, and $1.0 \mathrm{moL} \mathrm{dm}^{-3} \mathrm{NaCl}$. Before the film growth, the surface of the ITO electrode was purified by electrolysis of water for 3-5 min. The obtained film was transparent with a thickness of around $1 \mu \mathrm{m}$. Chemical compositions of the films were determined by the inductively coupled plasma (ICP) method and CHN organic elementary analysis (Perkin-Elmer 2400 CHN Elemental Analyzer). The $\mathrm{Li}^{+}$was substituted for $\mathrm{Na}^{+}$by performing the 


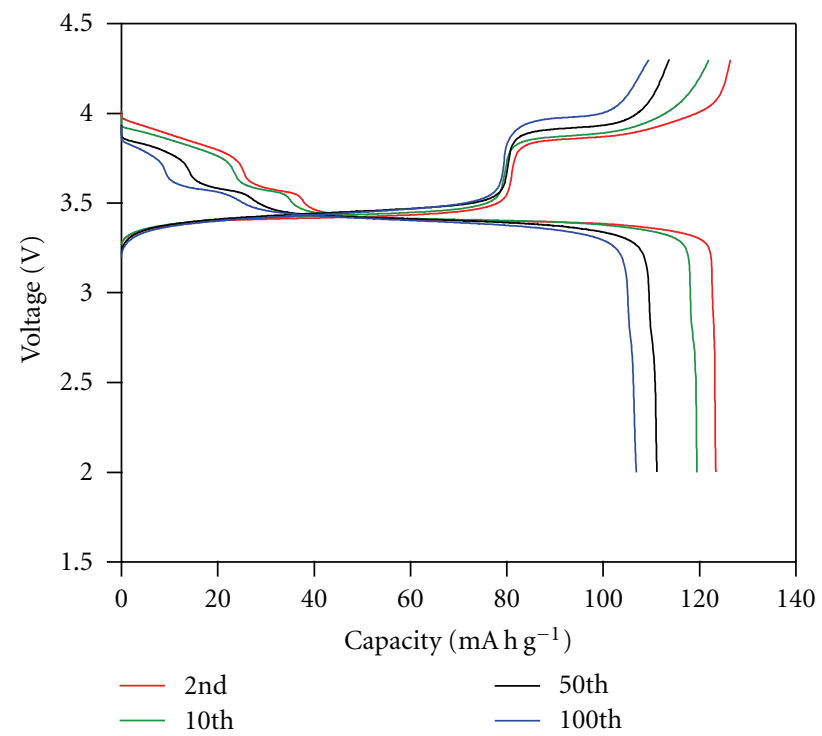

FIGURE 2: Charge/discharge curves of the film-type electrode of $\mathrm{Li}_{x} \mathrm{Mn}\left[\mathrm{Fe}(\mathrm{CN})_{6}\right]_{0.83} \cdot 3.5 \mathrm{H}_{2} \mathrm{O}$ against the Li metal at the 2nd, 10th, 50th, and 100 th cycles at a constant current density of $56 \mathrm{~mA} \mathrm{~g}^{-1}$.

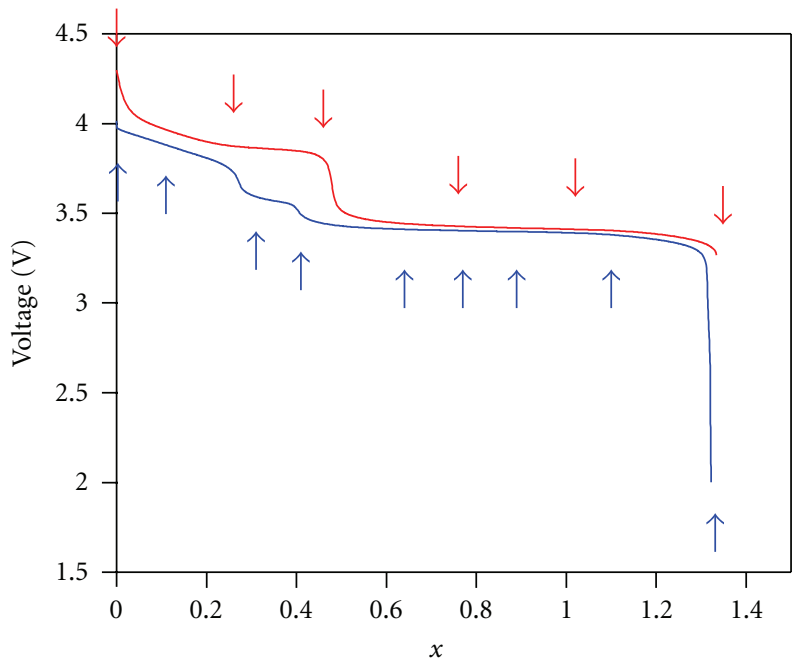

Figure 3: Voltage versus composition curves for charge (red) and discharge (blue) process of film-type electrode of $\mathrm{Li}_{x} \mathrm{Mn}\left[\mathrm{Fe}(\mathrm{CN})_{6}\right]_{0.83}$. $3.5 \mathrm{H}_{2} \mathrm{O}$ at the $2 \mathrm{nd}$ cycle. The arrows indicate the compositions for the XAS and XRD measurements.

charge/discharge cycles of the thin film against Li. Thus, we obtained thin films of $\mathrm{Li}_{x} \mathrm{Mn}\left[\mathrm{Fe}(\mathrm{CN})_{6}\right]_{0.83} \cdot 3.5 \mathrm{H}_{2} \mathrm{O}$.

\subsection{Electrochemical Measurements. To measure the charge/} discharge curves, the powder samples were ground with $20 \mathrm{wt} \%$ acetylene black and $5 \mathrm{wt} \%$ PTFE into a paste. The paste was coated on a stainless steel mesh and used as the cathode. Hereafter, we call this type of electrode a pastetype electrode. The thin film was used as prepared (filmtype electrode). The lithium metal was used as the reference and counter electrode, and the cutoff voltage was from 2.0 to $4.3 \mathrm{~V}$. The electrolyte was ethylene carbonate (EC)/diethyl carbonate (DEC) solution containing $1 \mathrm{~mol} \mathrm{dm}^{-1} \mathrm{LiClO}_{4}$.
2.4. X-Ray Absorption Measurements. The valence states of the Fe and Mn sites were determined by the ex situ X-ray absorption spectra (XAS) around the Mn and Fe K-edge. The XAS measurements were conducted at the beamline $7 \mathrm{C}$ of KEK-PF. The XAS spectra were recorded by a Lytle detector in a fluorescent yield mode with an $\mathrm{Si}(111)$ double-crystal monochromator at $300 \mathrm{~K}$. The background subtraction and normalization were done using ATHENA program [16].

2.5. Powder X-Ray Diffraction Measurements. The ex situ powder X-ray diffraction (XRD) patterns were measured at the beamline $8 \mathrm{~A}$ of KEK-PF equipped with an imaging plate detector. The charged/discharged samples were washed with 


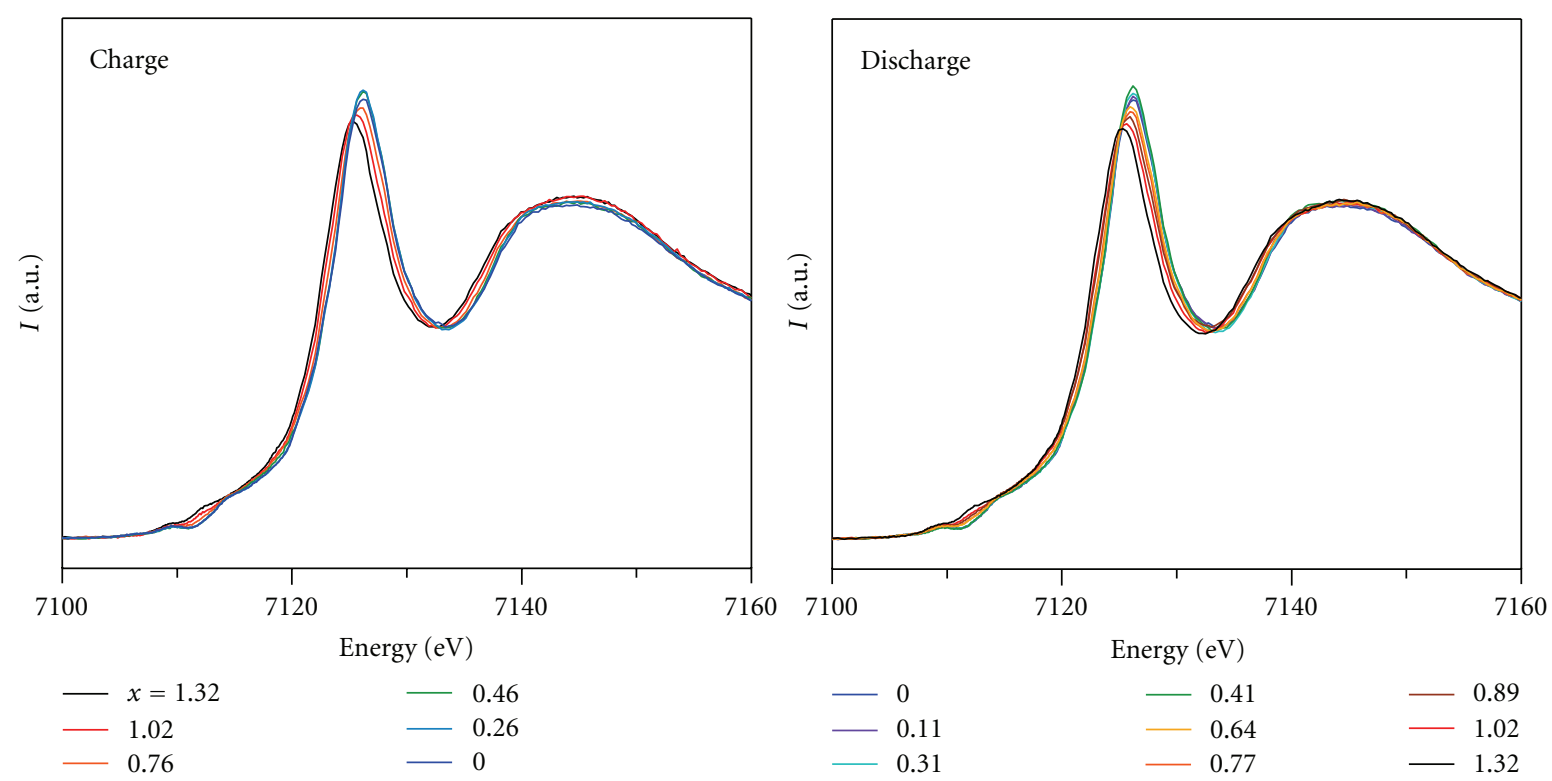

(a)

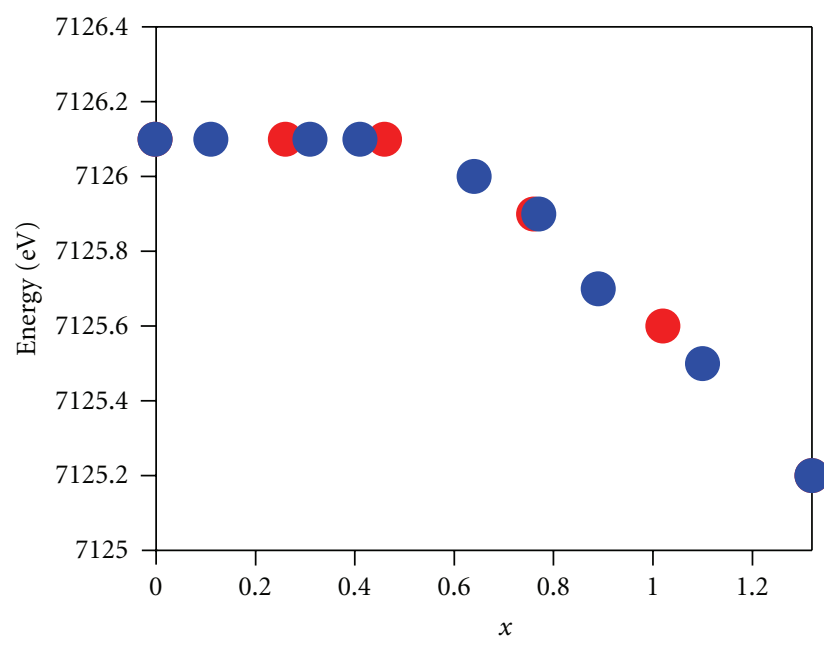

(b)

Figure 4: (a) Fe K-edge XAS spectra for the charge (left) and discharge (right) processes of film-type electrode of $\mathrm{Li}_{x} \mathrm{Mn}\left[\mathrm{Fe}(\mathrm{CN})_{6}\right]_{0.83}$. $3.5 \mathrm{H}_{2} \mathrm{O}$. (b) Peak energy $(E(x))$ against $x$ for the charge (red) and discharge (blue) processes.

DEC and were carefully removed from the ITO glasses. The obtained powders were sealed in $300 \mu \mathrm{m}$ glass capillaries. XRD patterns were measured at $300 \mathrm{~K}$ and the exposure time was $5 \mathrm{~min}$. Wavelength of the X-ray was $0.77516 \AA$. The lattice constants of each compounds were refined by the RIETAN-FP program [17].

\section{Results}

3.1. Charge/Discharge Property of the Paste-Type Electrode. Figure 1 shows the charge-discharge curves for the pastetype electrodes of $\mathrm{Na}_{4 x-2} M\left[\mathrm{Fe}(\mathrm{CN})_{6}\right]_{x} \cdot z \mathrm{H}_{2} \mathrm{O}(M=\mathrm{Mn}$, $\mathrm{Co}, \mathrm{Ni}$, and $\mathrm{Cu}$ ). The charge capacity of the 1 st cycle for
$M=\mathrm{Mn}, \mathrm{Co}, \mathrm{Ni}$, and $\mathrm{Cu}$ was $125,138,61,47 \mathrm{~mA} \mathrm{~h} \mathrm{~g}^{-1}$, respectively, while the discharge capacity of the 1st cycle for $M=\mathrm{Mn}, \mathrm{Co}, \mathrm{Ni}$, and $\mathrm{Cu}$ was $125,76,63$, and $71 \mathrm{~mA} \mathrm{~h} \mathrm{~g}^{-1}$, respectively. The charge/discharge capacity of $M=\mathrm{Mn}$ is nearly twice as large as the $M=\mathrm{Ni}$ and $\mathrm{Cu}$. This suggests that the two-electron reaction occurs in $M=\mathrm{Mn}$, while the one-electron reaction occurs in $M=\mathrm{Ni}$, and $\mathrm{Cu}$. The charge capacity of $M=$ Co is also twice as large as $M=\mathrm{Ni}$ and $\mathrm{Cu}$, while discharge capacity is almost the half of the charge capacity. This suggests that $M=$ Co shows irreversible two-electron reaction. Thus observed behaviors are almost same as the reported $M\left[\mathrm{Fe}(\mathrm{CN})_{6}\right]_{2 / 3} \cdot z \mathrm{H}_{2} \mathrm{O}$ type compounds $[12,13]$. The cyclability was far from excellent for every 


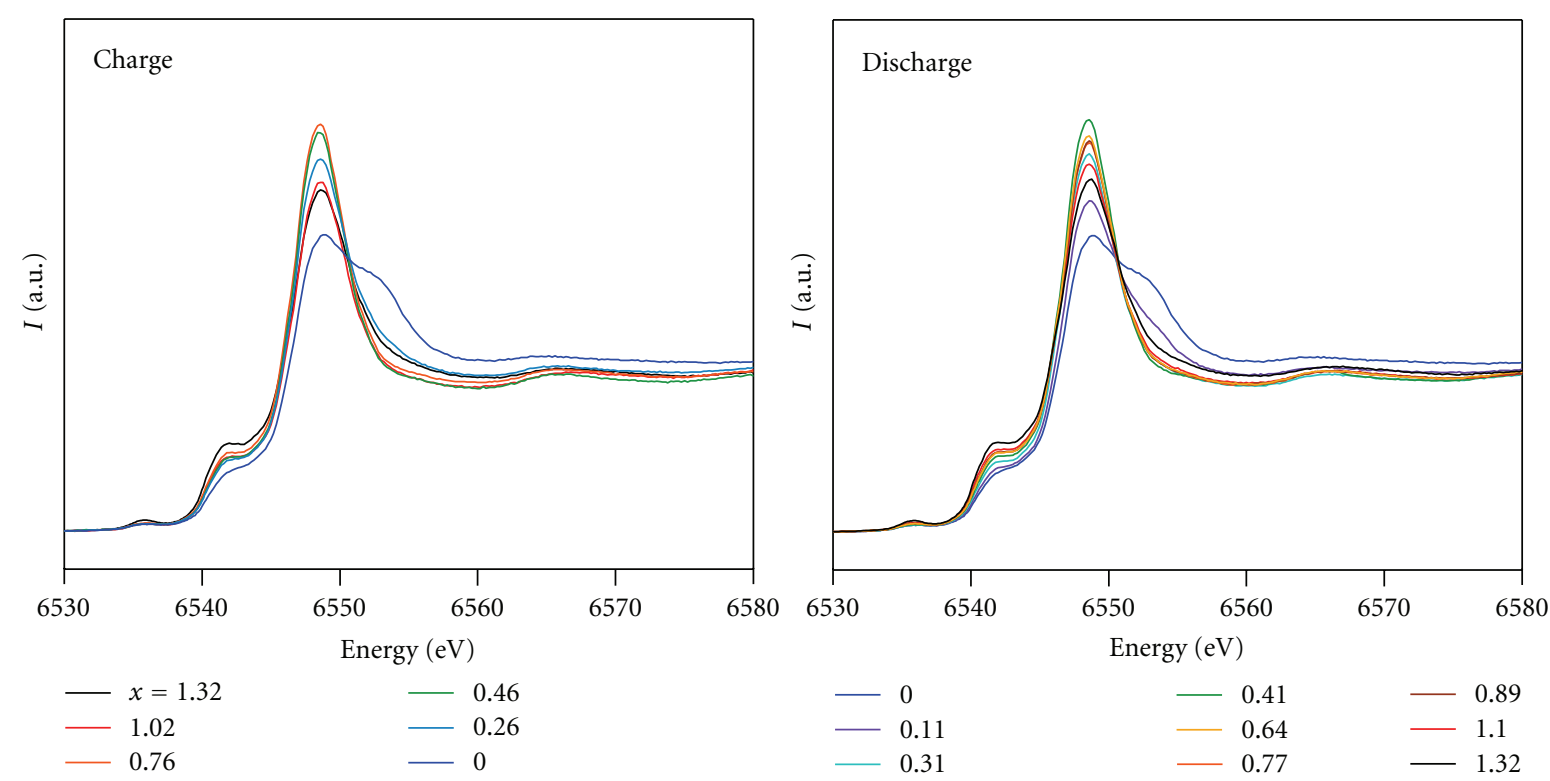

(a)

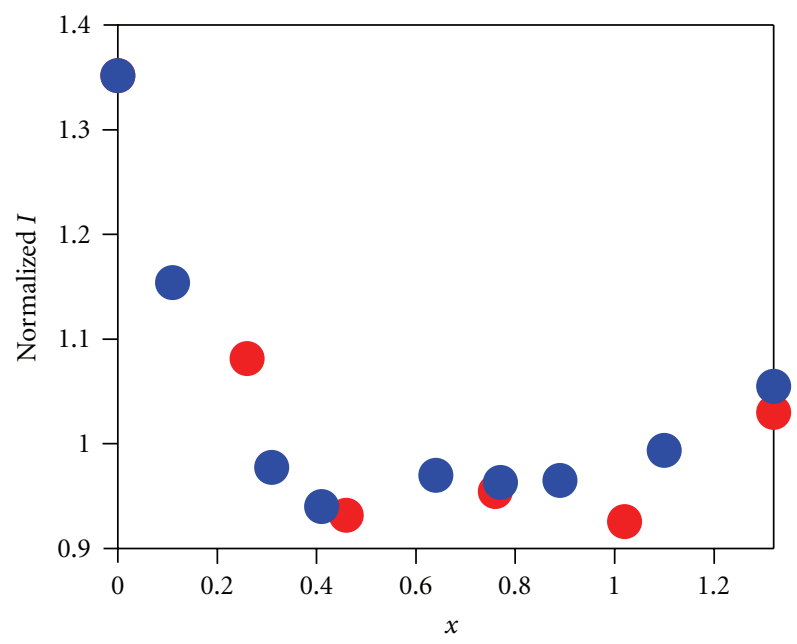

(b)

Figure 5: (a) Mn K-edge XAS spectra for the charge (left) and discharge (right) processes of film-type electrode of $\mathrm{Li}_{x} \mathrm{Mn}\left[\mathrm{Fe}(\mathrm{CN})_{6}\right]_{0.83}$. $3.5 \mathrm{H}_{2} \mathrm{O}$. (b) Normalized intensity $(I(x))$ against $x$ for the charge (red) and discharge (blue) processes.

compound. In other words, the paste-type electrodes of $\mathrm{Na}_{4 x-2} M\left[\mathrm{Fe}(\mathrm{CN})_{6}\right]_{x} \cdot z \mathrm{H}_{2} \mathrm{O}$ powders are not good candidates for the Li-ion battery cathodes.

3.2. Charge/Discharge Property of the Film-Type Electrode. Figure 2 shows the charge/discharge curves of the film-type electrode of $\mathrm{Li}_{x} \mathrm{Mn}\left[\mathrm{Fe}(\mathrm{CN})_{6}\right]_{0.83} \cdot 3.5 \mathrm{H}_{2} \mathrm{O}$ at the 2nd, 10th, 50th, and 100th cycles. In the charge process, electrochemical reaction takes place at 3.4 and $3.9 \mathrm{~V}$, and the charge capacity reaches $128 \mathrm{~mA} \mathrm{~h} \mathrm{~g}^{-1}$. The 3.4 and 3.9 plateaus correspond to the $\left[\mathrm{Fe}^{\mathrm{II}}(\mathrm{CN})_{6}\right]^{4-} /\left[\mathrm{Fe}^{\mathrm{III}}(\mathrm{CN})_{6}\right]^{3-}$ and $\mathrm{Mn}^{2+} / \mathrm{Mn}^{3+}$ reactions, respectively (vide infra). In the discharge process, electrochemical reaction takes place at 3.9, 3.6, and $3.4 \mathrm{~V}$. After 100 charge/discharge cycles, the charge capacity remains high
( $87 \%$ of the initial value). We emphasize that the thinfilm electrode shows a prominent color change from brown to colorless in the discharge process. The color charge can be used as a battery power indicator without electricity consumption. We call such a battery as color battery.

3.3. Variation of the Valence States. Figure 3 shows the charge/discharge curve of the film-type electrode of $\mathrm{Li}_{x} \mathrm{Mn}\left[\mathrm{Fe}(\mathrm{CN})_{6}\right]_{0.83} \cdot 3.5 \mathrm{H}_{2} \mathrm{O}$ at the 2 nd cycle. We electrochemically controlled the $\mathrm{Li}$ ion concentration $(x)$ as indicated by the arrows. Figure 4(a) shows the Fe K-edge XAS spectra of charge/discharge process. The absorption peak energies $(E)$ in the Fe K-edge spectra show clear blue shift with decrease in $x$ (Figure 4(b)). The blue shift is ascribed to the oxidization of $\mathrm{Fe}\left(\right.$ low-spin $\mathrm{Fe}^{\mathrm{II}} \rightarrow$ low-spin $\mathrm{Fe}^{\mathrm{III}}$ ) 


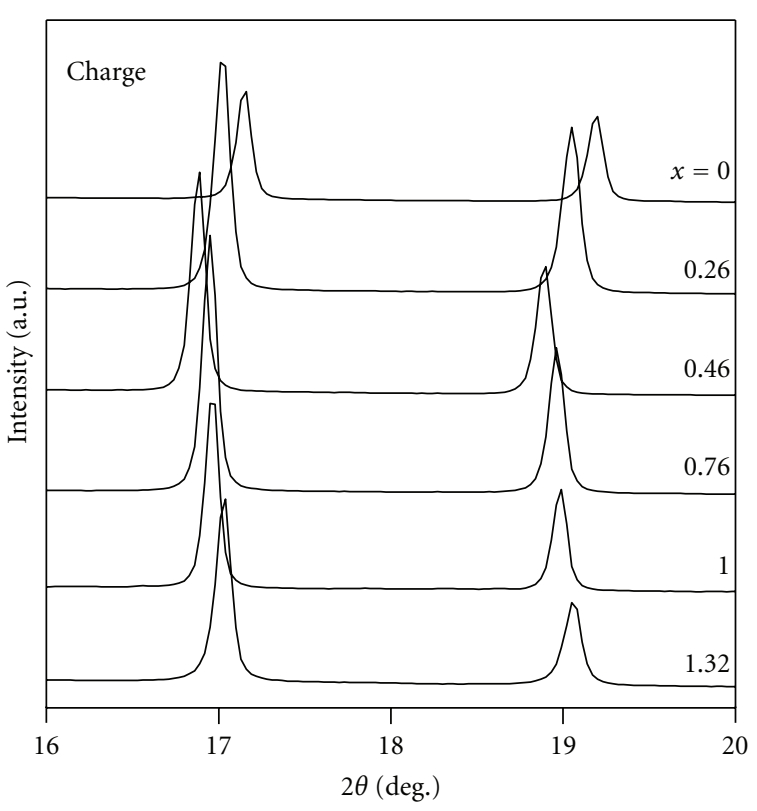

(a)

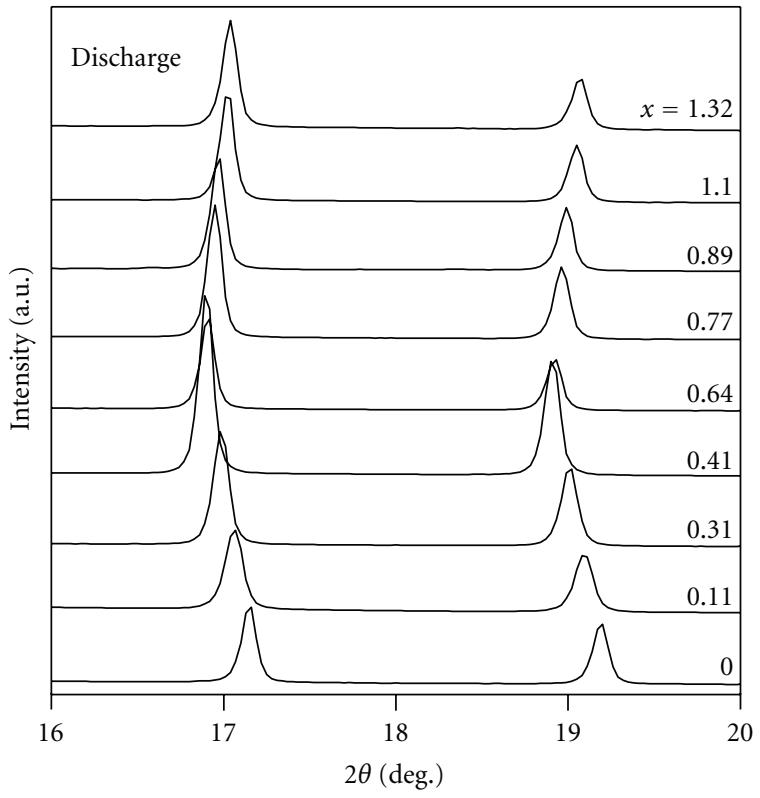

(b)

FIGURE 6: XRD patterns for the charge (left) and discharge (right) processes of film-type electrode of $\mathrm{Li}_{x} \mathrm{Mn}\left[\mathrm{Fe}(\mathrm{CN})_{6}\right]_{0.83} \cdot 3.5 \mathrm{H}_{2} \mathrm{O}$.

$[10,11]$. We emphasize that the blue shift saturates below $x=0.46(0.41)$ in the charge (discharge) process. Figure 5(a) shows the Mn K-edge XAS spectra of charge/discharge process. The shoulder peak appeared around $6553 \mathrm{eV}$ in the small- $x$ region. This new peak is ascribed to the oxidization of $\mathrm{Mn}$ (high spin $\mathrm{Mn}^{\mathrm{II}} \rightarrow$ high-spin $\mathrm{Mn}^{\mathrm{III}}$ ) [10]. These data indicated that the oxidization of Fe takes place in the large- $x$ region, while the oxidization of Mn takes place in the small- $x$ region.

3.4. Variation of the Structure. Figure 6 shows the magnified XRD patterns during charge/discharge process. The lattice structure remains the face-centered cubic $(F m-3 m ; Z=$ 4) throughout the charge/discharge process. In the charge process, the reflection shifts to the lower-angle side above $x=0.76$ while shifts to the lower-angle side below $x=0.46$. In the discharge process, the reflection shifts to the lowerangle side below $x=0.41$ while shifts to the higher-angle side above $x=0.64$.

\section{Discussion}

Now, let us evaluate the molar ratios, that is, $\mathrm{Fe}^{\mathrm{III}} /\left(\mathrm{Fe}^{\mathrm{II}}+\mathrm{Fe}^{\mathrm{III}}\right)$ and $\mathrm{Mn}^{\mathrm{III}} /\left(\mathrm{Mn}^{\mathrm{II}}+\mathrm{Mn}^{\mathrm{III}}\right)$, against $x$ based on the XAS spectra. Figure 4(b) shows peak energies $(E(x))$ in the Fe K-edge spectra against $x$. We note that the $E(x)$ is nearly constant below $x \sim 0.5$, suggesting that all the Fe sites are trivalent in this region. We ascribed the $E(x)$ values at $x=1.32$ and at $x=0.0$ is to the $\mathrm{Fe}^{\mathrm{II}}$ and $\mathrm{Fe}^{\mathrm{III}}$ state. With assuming a linear relation between $E(x)$ and the molar ratio, we obtained the formula $\mathrm{Fe}^{\mathrm{III}} /\left(\mathrm{Fe}^{\mathrm{II}}+\mathrm{Fe}^{\mathrm{III}}\right)=(E(x)-E(1.32)) /(E(0.0)-$ $E(1.32))$. Figure $5(\mathrm{~b})$ shows the normalized intensity $(I(x))$ at $6553.2 \mathrm{eV}$, which is ascribed to the $\mathrm{Mn}^{\mathrm{III}}$, in the Mn K-edge spectra against $x$. We note that the $I(x)$ is nearly constant above $x \sim 0.5$, suggesting that all the $\mathrm{Mn}$ sites remains divalent in this region. On the basis of the chemical formula and charge neutrality, we assumed the molar ratio of $\mathrm{Mn}^{\mathrm{III}}$ at $x=0.0$ is 0.49 . With assuming a linear relation between $I(x)$ and the molar ratio, we obtained the formula $\mathrm{Mn}^{\mathrm{III}} /\left(\mathrm{Mn}^{\mathrm{II}}+\right.$ $\left.\mathrm{Mn}^{\mathrm{III}}\right)=0.49 \times(I(x)-I(0.76)) /(I(0.0)-I(0.76))$.

Figures 7 (a) and 7(b) show the molar ratios of the Fe $\mathrm{F}^{\mathrm{III}}$ and $\mathrm{Mn}^{\mathrm{III}}$ against $x$, respectively. These data clearly indicate that the charge/discharge process of the film-type electrode consists of the two reactions, that is, $\mathrm{Mn}^{\mathrm{II}} / \mathrm{Mn}^{\mathrm{III}}$ and $\mathrm{Fe}^{\mathrm{II}} / \mathrm{Fe}^{\mathrm{III}}$ reactions. The $\mathrm{Mn}^{\mathrm{II}} / \mathrm{Mn}^{\mathrm{III}}$ reaction takes place in the small$x$ region $(x<0.49$ : indicated by vertical broken line in Figure 7 ), while the $\mathrm{Fe}^{\mathrm{II}} / \mathrm{Fe}^{\mathrm{III}}$ reaction takes place in the large$x$ region $(x>0.49)$. The first and second plateaus in the charge process (see Figure 3 ) are ascribed to the oxidization of $\mathrm{Mn}^{\mathrm{II}}$ and $\left[\mathrm{Fe}^{\mathrm{II}}(\mathrm{CN})_{6}\right]^{4-}$, respectively. On the contrary, the first, second, and third plateaus in the discharge process are due to the reduction of $\mathrm{Mn}^{\mathrm{III}}, \mathrm{Mn}^{\mathrm{III}}$, and $\left[\mathrm{Fe}^{\mathrm{III}}(\mathrm{CN})_{6}\right]^{3-}$, respectively.

Figure $7(\mathrm{c})$ shows the lattice constant against $x$. The lattice constants were refined by the Rietveld analyses. In the $\mathrm{Mn}^{\mathrm{II}} / \mathrm{Mn}^{\mathrm{III}}$ redox region, the lattice constant increases with $x$. The increase is ascribed to the larger ionic radius of $\mathrm{Mn}^{\mathrm{II}}$. In the $\mathrm{Fe}^{\mathrm{II}} / \mathrm{Fe}^{\mathrm{III}}$ region, the lattice constant decreases with $x$. The decrease is ascribed to the smaller size of $\left[\mathrm{Fe}^{\mathrm{II}}(\mathrm{CN})_{6}\right]^{4-}$ as compared with that of $\left[\mathrm{Fe}^{\mathrm{III}}(\mathrm{CN})_{6}\right]^{3-}$. Figure 8 shows the schematic illustration [18] of the crystal structure during the whole charge/discharge process.

\section{Conclusions}

In summary, we investigated the charge/discharge properties, electronic states, and structural properties of the film-type electrode of $\mathrm{Li}_{x} \mathrm{Mn}\left[\mathrm{Fe}(\mathrm{CN})_{6}\right]_{0.83} \cdot 3.5 \mathrm{H}_{2} \mathrm{O}$. The film-type 

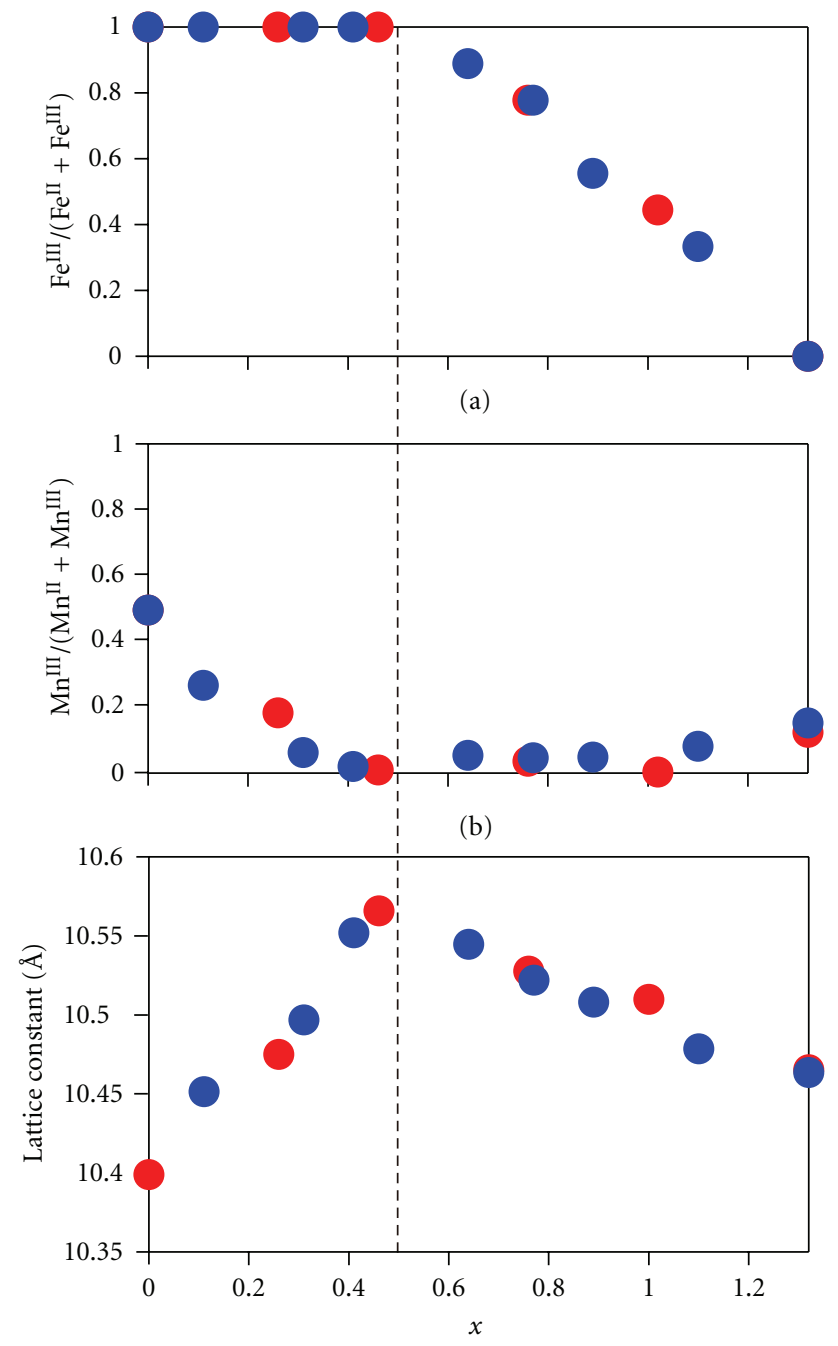

(c)

Figure 7: (a) Molar ratios of the $\mathrm{Fe}^{\mathrm{III}}$, (b) molar ratios of the $\mathrm{Mn}^{\mathrm{III}}$ (b), and (c) lattice constants for the charge (red) and discharge (blue) processes of $\mathrm{Li}_{x} \mathrm{Mn}\left[\mathrm{Fe}(\mathrm{CN})_{6}\right]_{0.83} \cdot 3.5 \mathrm{H}_{2} \mathrm{O}$.

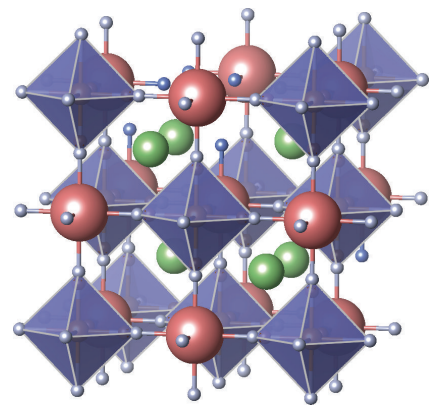

$x=1.32$

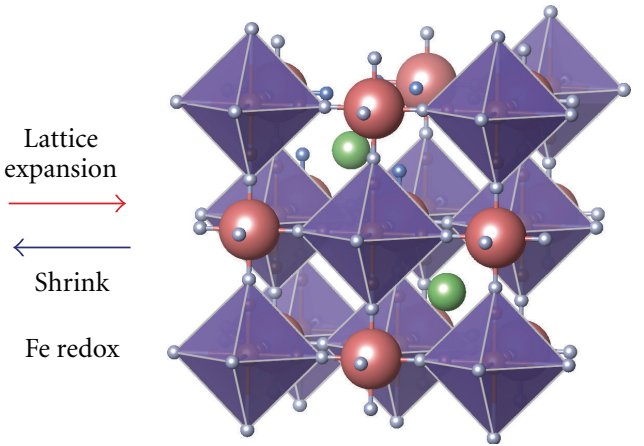

$x=0.49$

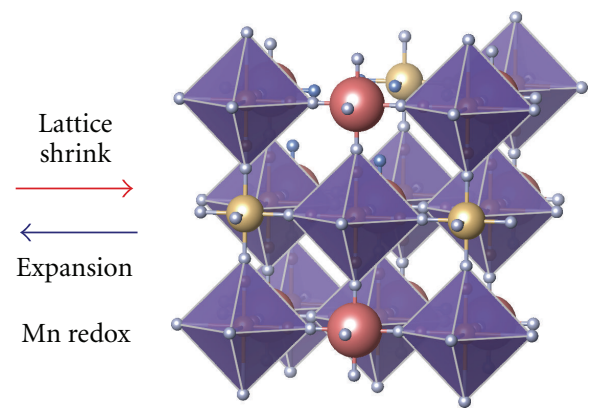

$x=0$

FIGURE 8: Schematic illustrations of crystal structures of $\mathrm{Li}_{x} \mathrm{Mn}\left[\mathrm{Fe}(\mathrm{CN})_{6}\right]_{0.83} \cdot 3.5 \mathrm{H}_{2} \mathrm{O}$ thin film. Blue and purple polyhedra represent $\left[\mathrm{Fe}^{\mathrm{II}}(\mathrm{CN})_{6}\right]$, and $\left[\mathrm{Fe}^{\mathrm{II}}(\mathrm{CN})_{6}\right]$ units, respectively, and red and yellow spheres represent $\mathrm{Mn}^{\mathrm{II}}$ and $\mathrm{Mn}^{\mathrm{III}}$, respectively. The green, white, and blue spheres are $\mathrm{Li}, \mathrm{N}$, and $\mathrm{O}$, respectively. 
electrode shows a large capacity and a good cyclability and is a candidate for Li-ion battery cathode. The XAS clearly indicated the two-electron redox process of $\mathrm{Fe}$ and $\mathrm{Mn}$. Nevertheless, the crystal structure remains cubic in the whole charge/discharge process. We ascribed the good charge/discharge property to the two-electron process without structural phase transition.

\section{Acknowledgments}

This paper was supported by a Grant-in-Aid (21244052) for Scientific Research from the Ministry of Education, Culture, Sports, Science and Technology. Elementary analysis was performed at Chemical Analysis Division, Research Facility Center for Science and Engineering, University of Tsukuba. The X-ray powder diffraction and X-ray absorption experiments were performed under the approval of the Photon Factory Program Advisory Committee (Proposal no. 2010G502 and 2011G501).

\section{References}

[1] M. Armand and J. M. Tarascon, "Building better batteries," Nature, vol. 451, no. 7179, pp. 652-657, 2008.

[2] H. Nishide and K. Oyaizu, "Toward flexible batteries," Science, vol. 319, no. 5864, pp. 737-738, 2008.

[3] A. K. Padhi, K. S. Nanjundaswamy, and J. B. Goodenough, "Phospho-olivines as positive-electrode materials for rechargeable lithium batteries," Journal of the Electrochemical Society, vol. 144, no. 4, pp. 1188-1194, 1997.

[4] P. Gibot, M. Casas-Cabanas, L. Laffont et al., "Roomtemperature single-phase Liinsertion/extraction in nanoscale $\mathrm{Li}_{x} \mathrm{FePO}_{4}$," Nature Materials, vol. 7, no. 9, pp. 741-747, 2008.

[5] M. Verdaguer, A. Bleuzen, V. Marvaud et al., "Molecules to build solids: high $T_{c}$ molecule-based magnets by design and recent revival of cyano complexes chemistry," Coordination Chemistry Reviews, vol. 190-192, pp. 1023-1047, 1999.

[6] A. Ludi and H. U. Güdel, "Structural chemistry of polynuclear transition metal cyanides," Structure and Bonding, vol. 14, pp. 1-21, 1973.

[7] K. Itaya, T. Ataka, and S. Toshima, "Spectroelectrochemistry and electrochemical preparation method of Prussian Blue modified electrodes," Journal of the American Chemical Society, vol. 104, no. 18, pp. 4767-4772, 1982.

[8] T. Matsuda, J. Kim, and Y. Moritomo, "Symmetry switch of cobalt ferrocyanide framework by alkaline cation exchange," Journal of the American Chemical Society, vol. 132, no. 35, pp. 12206-12207, 2010.

[9] Y. Moritomo, Y. Kurihara, T. Matsuda, and J. E. Kim, "Structural phase diagram of $\mathrm{Mn}-\mathrm{Fe}$ cyanide against cation concentration," Journal of the Physical Society of Japan, vol. 80, no. 10, Article ID 103601, 2011.

[10] T. Yokoyama, H. Tokoro, S. I. Ohkoshi, K. Hashimoto, K. Okamoto, and T. Ohta, "Photoinduced phase transition of $\mathrm{RbMnFe}(\mathrm{CN})_{6}$ studied by $\mathrm{x}$-ray-absorption fine structure spectroscopy," Physical Review B, vol. 66, no. 18, Article ID $184111,2002$.

[11] A. Omura, Y. Kurihara, T. Matsuda, H. Tanida, T. Uruga, and Y. Moritomo, "Cation extraction process in bilayer cyanide film as investigated by depth-resolved X-ray absorption spectroscopy," Japanese Journal of Applied Physics, vol. 50, no. 12, Article ID 125802, 2011.
[12] N. Imanishi, T. Morikawa, J. Kondo et al., "Lithium intercalation behavior into iron cyanide complex as positive electrode of lithium secondary battery," Journal of Power Sources, vol. 79, no. 2, pp. 215-219, 1999.

[13] N. Imanishi, T. Morikawa, J. Kondo et al., "Lithium intercalation behavior of iron cyanometallates," Journal of Power Sources, vol. 81-82, pp. 530-534, 1999.

[14] M. Okubo, D. Asakura, Y. Mizuno et al., "Switching redoxactive sites by valence tautomerism in prussian blue analogues $\mathrm{A}_{x} \mathrm{Mn}_{y}\left[\mathrm{Fe}(\mathrm{CN})_{6}\right] \cdot n \mathrm{H}_{2} \mathrm{O}(\mathrm{A}: \mathrm{K}, \mathrm{Rb})$ : Robust frameworks for reversible Li storage," Journal of Physical Chemistry Letters, vol. 1, no. 14, pp. 2063-2071, 2010.

[15] T. Matsuda and Y. Moritomo, "Thin film electrode of Prussian blue analogue for Li-ion battery," Applied Physics Express, vol. 4, no. 4, Article ID 047101, 2011.

[16] B. Ravel and M. Newville, "ATHENA, ARTEMIS, HEPHAESTUS: Data analysis for X-ray absorption spectroscopy using IFEFFIT," Journal of Synchrotron Radiation, vol. 12, no. 4, pp. 537-541, 2005.

[17] F. Izumi and K. Momma, "Three-dimensional visualization in powder diffraction," Solid State Phenomena, vol. 130, pp. 1520, 2007.

[18] K. Momma and F. Izumi, "VESTA 3 for three-dimensional visualization of crystal, volumetric and morphology data," Journal of Applied Crystallography, vol. 44, no. 6, pp. 12721276, 2011. 

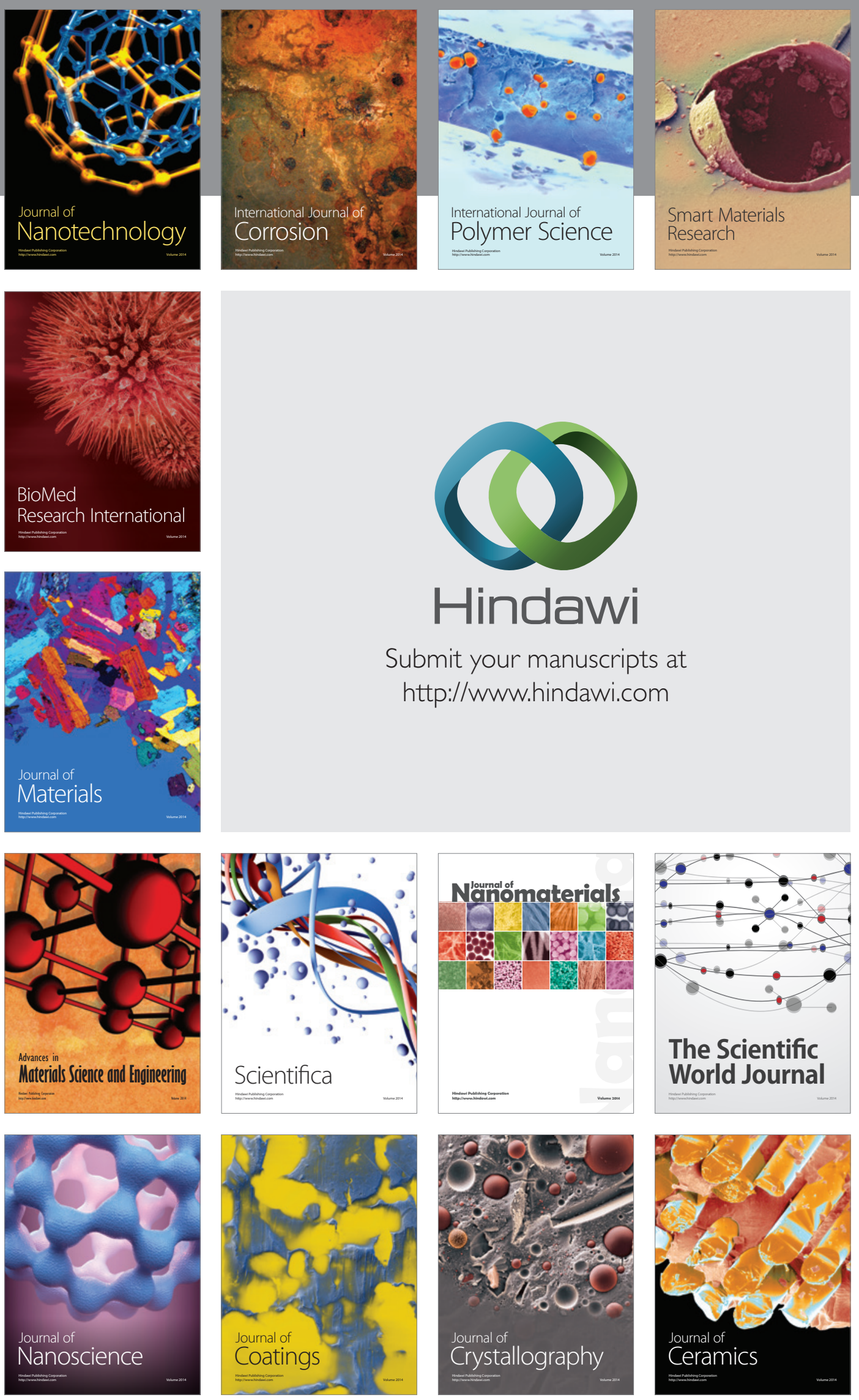

The Scientific World Journal

Submit your manuscripts at

http://www.hindawi.com

\section{World Journal}

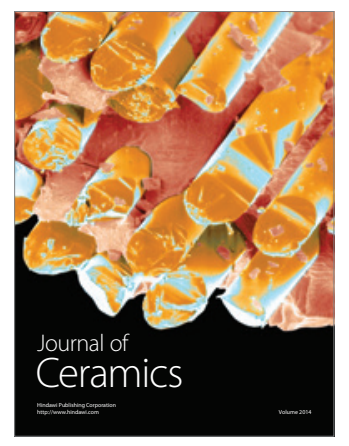

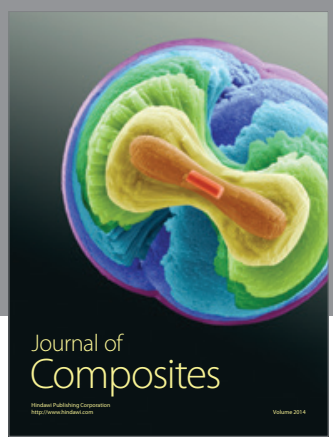
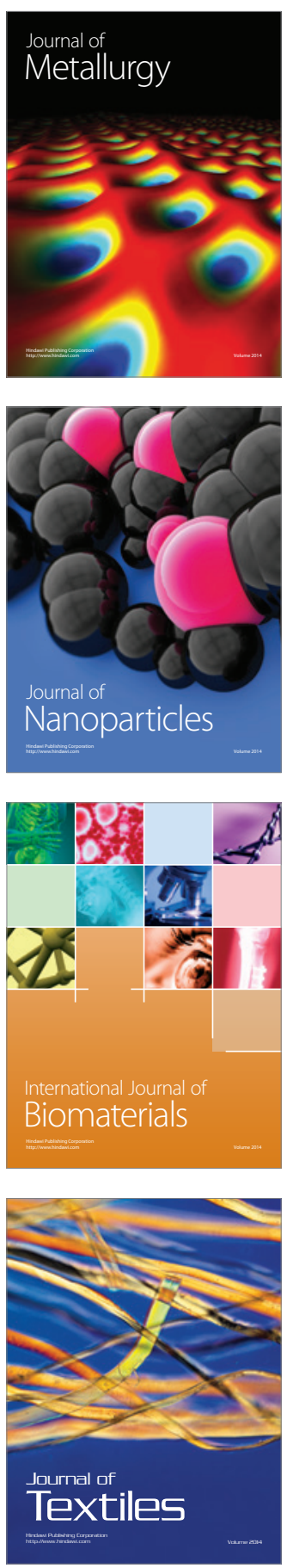